\title{
Increased Expression of Programmed Death-Ligand 1 in Infiltrating Immune Cells in Hepatocellular Carcinoma Tissues after Sorafenib Treatment
}

\author{
Li-Chun Lu ${ }^{a}$, b,g Yi-Hsuan Lee ${ }^{c}$ Chun-Jung Chang ${ }^{a}$ Chia-Tung Shun ${ }^{c, d}$ \\ Chih-Yeu Fang $^{f}$ Yu-Yun Shao ${ }^{a, b, g}$ Tsung-Hao Liub, h \\ Ann-Lii Cheng a, b, e, g Chih-Hung Hsu ${ }^{a, b}$ \\ a Graduate Institute of Oncology, National Taiwan University College of Medicine, Taipei, \\ Taiwan, ROC; ${ }^{b}$ Department of Oncology, National Taiwan University Hospital, Taipei, Taiwan, \\ ROC; ' ${ }^{\text {Department }}$ of Pathology, National Taiwan University Hospital, Taipei, Taiwan, ROC; \\ ${ }^{\mathrm{d}}$ Department of Forensic Medicine, National Taiwan University Hospital, Taipei, Taiwan, ROC; \\ e Department of Internal Medicine, National Taiwan University Hospital, Taipei, Taiwan, ROC; \\ fDepartment of Pathology, Wan Fan Hospital, Taipei Medical University, Taipei, Taiwan, ROC; \\ g National Taiwan University Cancer Center, Taipei, Taiwan, ROC; h Department of Internal \\ Medicine, National Taiwan University Hospital Hsin-Chu Branch, Hsinchu, Taiwan, ROC
}

\section{Keywords}

Hepatocellular carcinoma - Macrophage · Programmed death-ligand $1 \cdot$ Sorafenib · Tumor microenvironment

\begin{abstract}
Objective: Programmed death-ligand 1 (PD-L1) expression in the tumor microenvironment (TME) has been reported to be related to prognosis in patients with hepatocellular carcinoma (HCC) after hepatectomy. The impact of sorafenib on PD-L1 expression in the TME of advanced HCC is unclear. Patients and Methods: Patients with HCC who received sorafenib for advanced disease at National Taiwan University Hospital, Taipei, Taiwan, and who had paired HCC tissues obtained before and after sorafenib treatment were included in the study group. HCC patients not treated with sorafenib who had paired primary and recurrent or metastatic tissues were identified as the reference group. The membrane PD-L1 staining, detected by immunohistochemistry (IHC) using SP142 antibody, was semiquantitatively scored in tumor cells (TCs) or tumor-infiltrating immune cells (ICs). Additional IHC assays were employed to
\end{abstract}

Ann-Lii Cheng and Chih-Hung Hsu contributed equally to senior authorship.

Chih-Hung Hsu, MD, PhD, and Ann-Lii Cheng, MD, PhD

Department of Oncology, National Taiwan University Hospital

7 Chung-Shan South Road

Taipei 10002 (Taiwan, ROC)

E-Mail chihhunghsu@ntu.edu.tw and alcheng@ntu.edu.tw 


\section{Liver Cancer}

characterize the PD-L1-expressing ICs. Results: Twenty-three advanced HCC patients with pre- and post-sorafenib paired HCC tissues were included in the study group. The median duration of sorafenib treatment was 4.3 months (range: 1.3-18.7). PD-L1 expression in ICs was significantly higher in post-sorafenib HCC tissues than in pre-sorafenib HCC tissues (presorafenib vs. post-sorafenib IHC 0/1/2/3: 11/5/5/2 vs. 5/5/2/11, $p=0.016$ ). However, PD-L1 expression in TCs was not significantly different between pre- and post-sorafenib tissues (IHC 0/1/2/3: 19/2/0/2 vs. 14/5/0/4, $p=0.094)$. In the reference group of 44 patients not treated with sorafenib, PD-L1 expression in ICs and TCs was not significantly different between the paired primary and metastatic HCC tissues. By performing IHC double staining with PD-L1 and CD68, we found the PD-L1-expressing ICs were mainly CD68-positive macrophages. PD-L1 expression levels of pre- and post-sorafenib tissues were not associated with patients' overall survival or duration of sorafenib treatment. Conclusions: PD-L1 expression in ICs was significantly increased in post-sorafenib HCC tissues. The mechanisms and clinical significance of this observation warrants further investigation.

(C) 2018 S. Karger AG, Basel

\section{Introduction}

Hepatocellular carcinoma (HCC), when presenting with advanced stage that is not amenable to locoregional therapies, is one of the most difficult to treat malignancies because of the limited treatment options. Sorafenib, a multikinase inhibitor with antiangiogenic property, was the first therapeutic agent approved for advanced HCC in 2007 [1, 2]. Recently, 2 large phase III trials have demonstrated that regorafenib and lenvatinib exhibit efficacies as second- and first-line systemic therapies for advanced HCC, respectively [3, 4]. Although these two multikinase inhibitors have enriched our armaments against HCC, sorafenib remains the most widely used systemic therapy for HCC.

Immunotherapy targeting the immune escape mechanisms of cancer has recently emerged as a new paradigm of cancer therapy [5]. Inhibitors of immune checkpoints, especially the programmed death-1 (PD-1)/programmed death-ligand 1 (PD-L1) monoclonal antibodies, have demonstrated clinical activities in melanoma and many other cancer types, including HCC [6-8]. A recent phase 1/2 clinical trial (CheckMate 040) showed a response rate of $15-20 \%$ for nivolumab, an anti-PD-1 monoclonal antibody, in patients of advanced HCC with or without prior sorafenib treatment [8]. Based on the results of this trial, nivolumab was granted accelerated approval for the treatment of HCC in patients who have been previously treated with sorafenib by Food and Drug Administration of the United States in September 2017. A phase III randomized trial testing nivolumab versus sorafenib in patients with treatment-naïve advanced HCC is ongoing. Furthermore, combinations of immune checkpoint inhibitors plus other therapies for HCC such as sorafenib are under active investigation.

Tumor microenvironment (TME), including the immune contexture, has been demonstrated to play significant roles in the development and progression of HCC [9, 10]. Previous studies have also suggested that the increased expression of PD-L1 in the TME of HCC was associated with tumor aggressiveness or recurrence in patients with HCC who received hepatectomy [11, 12]. Although sorafenib is a multikinase inhibitor mainly targeting RAF and vascular endothelial growth factor receptors, many studies have suggested that sorafenib may exhibit a variety of immunomodulatory effects [13-15]. Notably, upregulation of PD-L1 in HCC cells upon exposure to or in resistance to sorafenib has been recently reported in preclinical studies $[16,17]$. However, no study has ever reported whether or not sorafenib treatment affects PD-L1 expression in the TME of clinical HCC samples. 
Lu et al.: Increased PD-L1 Expression in ICs of HCC after Sorafenib

To understand PD-L1 expression patterns in tumor cells (TCs) and tumor-infiltrating immune cells (ICs) in HCC tissues that progressed after sorafenib treatment, we planned this study to analyze paired pre- and post-sorafenib HCC tissues by using immunohistochemistry (IHC) assays.

\section{Patients and Methods}

Study Population and Variables

In this study, we reviewed patients with advanced HCC who received sorafenib at National Taiwan University Hospital (NTUH), Taipei, Taiwan. Patients with paired HCC tissues obtained before and after sorafenib treatment were included in the study group. To evaluate the effect of disease progression per se on PD-L1 expression in the TME of HCC tissues, HCC patients not treated with sorafenib who had paired primary and metastatic HCC tissues were included as the reference group.

Clinical data were retrieved from medical records. The overall survival (OS) of the study group was calculated from the first prescription date of sorafenib to the date of death or the final follow-up day (October 10, 2016). The data of patients who survived were censored. Time to treatment discontinuation (TTD) of the study group was measured from the first to last prescription dates of sorafenib. This study was approved by the Research Ethics Committee of NTUH.

\section{IHC Analysis}

Formalin-fixed, paraffin-embedded tissue sections (5- $\mu \mathrm{m}$ thickness) of each patient were retrieved from archived tissues of the Department of Pathology, NTUH. Routine IHC procedures were performed. Briefly, tissue sections were deparaffinized, rehydrated, and heated in Tris-EDTA for antigen retrieval followed by blocking with hydrogen peroxide in combination with Ultra V Block (Thermo Fisher Scientific, CA, USA) to reduce nonspecific background staining. The slides were then incubated with primary antibodies, including anti-PD-L1 antibody clone SP142 (1:50, Spring Bioscience, Pleasanton, CA, USA), anti-human CD3 (1:100, clone 2GV6; Ventana, Tuscon, AZ, USA), CD66b (1:100, clone 80H3, OriGene, Rockville, MD, USA), CD68 (1:100, clone KP1, Ventana, Tuscon, AZ, USA), and CD163 (1:100, clone 10D6; Thermo Fisher Scientific, CA, USA), at $4{ }^{\circ} \mathrm{C}$ overnight. The expression signals were produced using appropriate secondary antibodies, followed by UltraVision Quanto Detection System HRP DAB (Thermo Fisher Scientific, CA, USA) according to the manufacturer's instructions. To determine the coexpression of PD-L1 and other surface markers, a modified, sequential multiplex IHC assay was performed by procedures as described previously [18].

Because the distribution of PD-L1-positive cells could be very focal and heterogeneous in a given sample, we included the whole slide, including tumor center, tumor margin, and peritumor stroma, for analysis of every sample. To determine PD-L1 expression on TCs and ICs, including lymphocytes, neutrophils, dendritic cells, and macrophages, at least 100 TCs or ICs were scrutinized independently in each slide. Membranous PD-L1 staining was scored as IHC $0,1,2$, or 3 if $<1 \%, \geq 1 \%$ but $<5 \%, \geq 5 \%$ but $<10 \%$, or $\geq 10 \%$ of cells were PD-L1 positive, respectively, for TCs and ICs according to previous publications $[19,20]$. All slides were evaluated and scored by pathologists Y.-H. Lee and C.-T. Shun, who were blinded to clinical data. For those with discordant results of PD-L1 IHC scoring between 2 pathologists, the slides were reviewed again by Y.-H. Lee and L.-C. Lu together, and consensus was reached to determine final scores.

\section{Immune Gene Expression Profiling by the nCounter Analysis System}

Selected pre- or post-sorafenib samples were analyzed for their immune-related gene expression profiles by the nCounter analysis system (NanoString Technologies Inc., Seattle, WA, USA). For each selected sample, at least $200 \mathrm{ng}$ of RNA was extracted. nCounter assays were performed according to the manufacturer's protocol. Briefly, RNA was hybridized to nCounter probes for 770 predefined genes of the PanCancer Immune Profiling Panel. The samples were then transferred to the nCounter Prep Station, where purification and immobilization were performed in the nCounter Cartridge. The data were collected using the nCounter Digital Analyzer. Finally, nSolver analysis software (V.3.00) was used to normalize and analyze the reported counts.

\section{Statistical Analyses}

Statistical analyses were performed using SAS statistical software (version 9.4, SAS Institute Inc., Cary, NC, USA). A two-sided $p$ value of $<0.05$ was considered statistically significant. The associations among the categorical variables of the groups of patients were analyzed using the $\chi^{2}$ test or Fisher's exact test, if suitable. 


\section{Liver Cancer}

Table 1. Patient characteristics of the study and reference groups

\begin{tabular}{|c|c|}
\hline \multicolumn{2}{|l|}{ Liver Cancer 2019;8:110-120 } \\
\hline DOI: $10.1159 / 000489021$ & $\begin{array}{l}\text { (c) } 2018 \text { S. Karger AG, Basel } \\
\text { www.karger.com/lic }\end{array}$ \\
\hline
\end{tabular}

\begin{tabular}{|c|c|c|c|}
\hline Variable & $\begin{array}{l}\text { Study group } \\
n(\%)\end{array}$ & $\begin{array}{l}\text { Reference group } \\
n(\%)\end{array}$ & $p$ value \\
\hline Total & $23(100.0)$ & $44(100.0)$ & \\
\hline Sorafenib treatment & $23(100.0)$ & $0(0)$ & \\
\hline Age & & & 0.299 \\
\hline$\geq 60$ years & $13(56.5)$ & $19(43.2)$ & \\
\hline$<60$ years & $10(43.5)$ & $25(56.8)$ & \\
\hline Sex & & & 1.000 \\
\hline Male & $20(87.0)$ & 37 (84.1) & \\
\hline Female & $3(13.0)$ & 7 (15.9) & \\
\hline HBsAg reactive & $15(65.2)$ & $33(75.0)$ & 0.399 \\
\hline Anti-HCV reactive & $2(8.7)$ & 7 (15.9) & 0.708 \\
\hline AFP & & & 0.395 \\
\hline$\geq 400 \mathrm{ng} / \mathrm{ml}$ & $6(26.1)$ & $16(36.4)$ & \\
\hline$<400 \mathrm{ng} / \mathrm{ml}$ & 17 (73.9) & $28(63.6)$ & \\
\hline Paired HCC tissue 1 & & & $<0.001$ \\
\hline From liver & $11(47.8)$ & $44(100)$ & \\
\hline From metastasis & $12(52.2)$ & $0(0)$ & \\
\hline Paired HCC tissue 2 & & & 0.343 \\
\hline From liver & $1(4.3)$ & $0(0)$ & \\
\hline From metastasis & $22(95.7)$ & $44(100.0)$ & \\
\hline
\end{tabular}

HBsAg, hepatitis virus B surface antigen; Anti-HCV, hepatitis C virus antibody; AFP, $\alpha$-fetoprotein; HCC, hepatocellular carcinoma.

A Wilcoxon signed rank test was used to compare the differences in PD-L1 expression between paired tissues. A multiple logistic regression model was used to analyze the effect of sorafenib on PD-L1 expression in paired HCC tissues. The OS and TTD of patients with high or low PD-L1 expression were estimated using the KaplanMeier method and compared using the log-rank test.

\section{Results}

Patient Characteristics

We screened 931 patients with advanced HCC who received sorafenib at NTUH between 2005 and 2015. Among them, only 31 patients had paired HCC tissues obtained before and after sorafenib treatment. Eight patients were excluded because of insufficient number of archived tissues for further analysis. Finally, 23 sorafenib-treated patients with paired HCC tissues were included in the study group. For comparison, previously identified 44 patients not treated with sorafenib with paired HCC tissues were included as the reference group. Their pertinent clinicopathological characteristics are listed in Table 1.

The study group included 23 sorafenib-treated HCC patients, with a median age of 64.7 years (male:female = 20:3). Among them, 65.2\% (15/23) of patients were hepatitis B virus surface antigen positive. The paired HCC tissues of all patients in the study group were obtained before and after sorafenib treatment (tissue 1 and tissue 2, respectively), and all post-sorafenib tissues were obtained when patients had confirmed disease progression. The median duration of sorafenib treatment was 4.3 months (range: 1.3-18.7). The median time between the date of tissue 1 procurement and the date of starting sorafenib was 5.9 months (range: 0.2-45.4). The median time from the last dosing date of sorafenib to the date of tissue 2 procurement was 0.3 months (range: $0-43.2$ ). The median time between the date of tissue 1 and tissue 2 procurement was 10.8 months (range: 2.0-64.4). Approximately half of the 


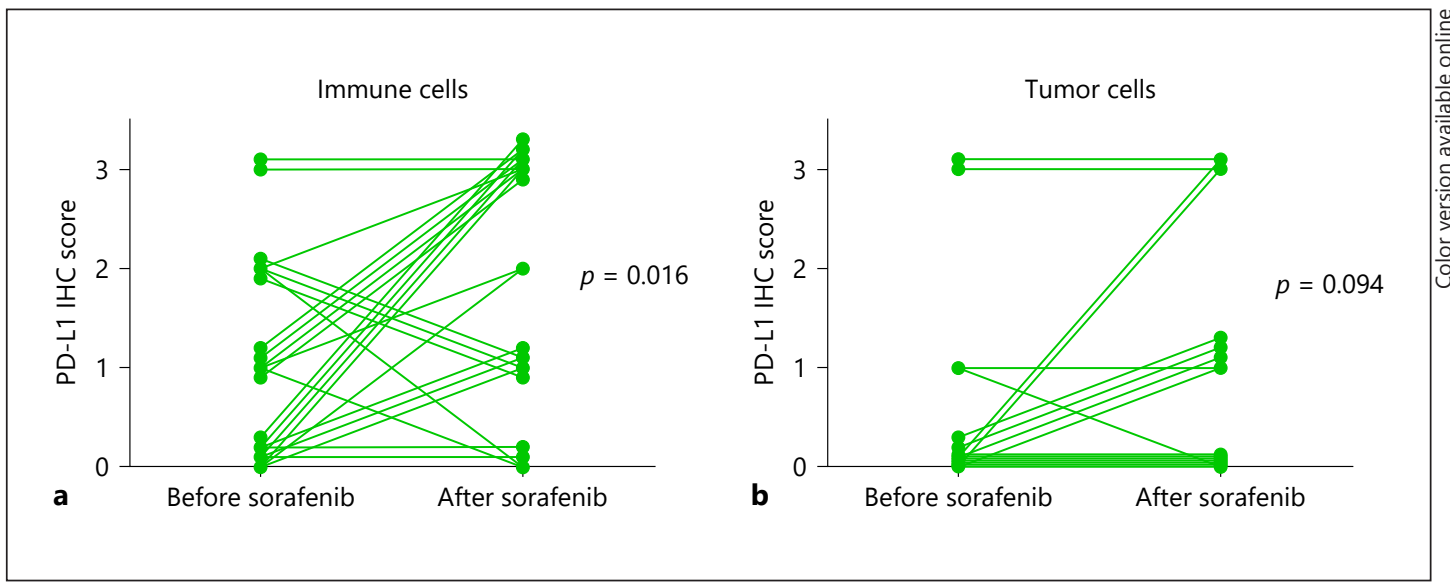

Fig. 1. Programmed death-ligand 1 (PD-L1) expression in tumor-infiltrating immune cells (a) and tumor cells (b) in paired hepatocellular carcinoma tissues before and after sorafenib treatment.

pre-sorafenib tissues (tissue 1, 11/23, 47.8\%) were obtained from the liver. By contrast, except for one, all post-sorafenib tissues (tissue 2, 22/23, 95.7\%) were obtained from metastatic tumors. In particular, half of the post-sorafenib metastatic tissues $(n=11)$ were obtained from the lung.

The reference group included 44 advanced HCC patients not treated with sorafenib who had paired HCC tissues obtained at different time points. All paired tissues comprised primary HCC tissues (tissue 1) obtained through hepatectomy and metastatic HCC tissues (tissue 2) obtained through metastasectomy upon recurrence. The median time between tissue 1 and tissue 2 procurement was 14.6 months (range: $3.3-81.1)$. A total of $36.4 \%(16 / 44)$ and $27.3 \%$ $(12 / 44)$ of the metastatic tissues (tissue 2) were obtained from the lung and soft tissues, respectively.

PD-L1 Expression in TCs and ICs in Paired HCC Tissues

In the study group, PD-L1 expression in ICs was significantly higher in post-sorafenib HCC tissues than in pre-sorafenib HCC tissues (pre-sorafenib vs. post-sorafenib IHC 0/1/2/3: $11 / 5 / 5 / 2$ vs. $5 / 5 / 2 / 11, p=0.016)$. However, PD-L1 expression in TCs was not significantly different between pre- and post-sorafenib tissues (IHC 0/1/2/3: 19/2/0/2 vs. 14/5/0/4, $p=$ 0.094; Fig. 1 and Table S1; see www.karger.com/doi/10.1159/000489021 for all supplementary material). PD-L1 expression levels (IHC $2 / 3$ vs. $0 / 1$ ) on ICs in pre- or post-sorafenib tissues were not associated with OS or TTD of sorafenib (Fig. 2). PD-L1 expression levels on TCs in pre- or post-sorafenib tissues did not predict OS or TTD either (data not shown).

In the reference group, PD-L1 expression in ICs was not significantly different between primary HCC tissues and metastatic HCC tissues (primary vs. metastatic IHC 0/1/2/3: $33 / 4 / 4 / 3$ vs. $26 / 8 / 3 / 7, p=0.185$ ). PD-L1 expression in TCs was nonsignificantly higher in metastatic HCC tissues than in primary HCC tissues (primary vs. metastatic IHC $0 / 1 / 2 / 3$ : $41 / 2 / 1 / 0$ vs. $36 / 4 / 2 / 2, p=0.090$ ). Overall, most HCC tissues of the reference group showed negative PD-L1 expression (IHC 0) in ICs (primary vs. metastatic tissues: 75.0 vs. 59.1\%) and TCs (93.2 vs. $81.2 \%$ ).

All tissue 1 samples of the reference group were obtained from the liver, but only approximately half of the tissue 1 samples of the study group were obtained from the liver (Table 1). We adjusted for the effect of imbalanced origins of tissue 1 between the study and reference 
Lu et al.: Increased PD-L1 Expression in ICs of HCC after Sorafenib

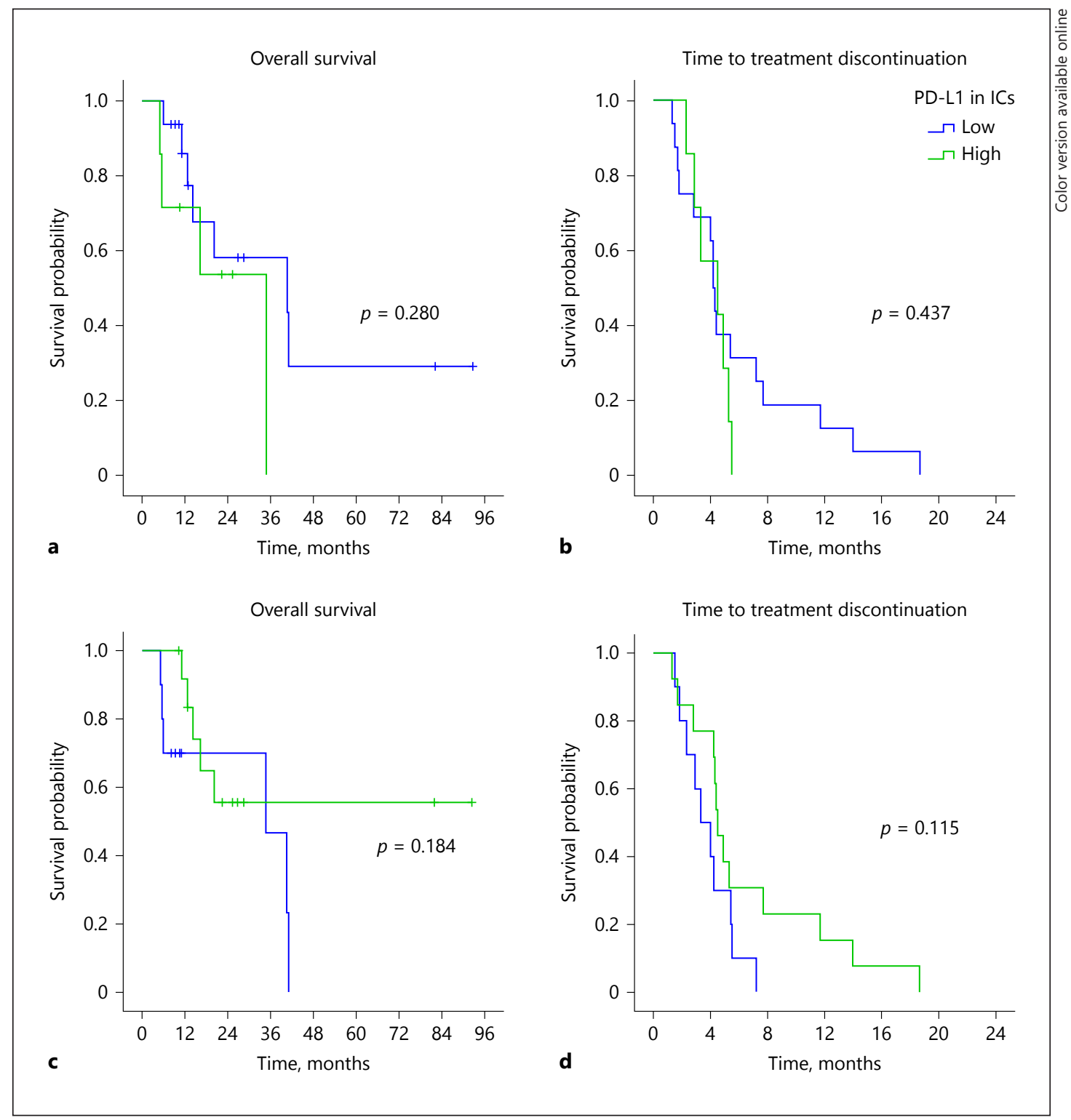

Fig. 2. Kaplan-Meier curves of overall survival (a, c) and time to treatment discontinuation (b, d) of advanced hepatocellular carcinoma patients with low programmed death-ligand 1 (PD-L1) expression (IHC 0/1) and high PD-L1 expression (IHC 2/3) in tumor-infiltrating immune cells (ICs) before (a, b) and after (c, d) sorafenib treatment.

groups by using a multiple logistic regression model. We found that sorafenib treatment was still significantly associated with increased PD-L1 expression in ICs (increased PD-L1 expression vs. stable or decreased PD-L1 expression in ICs, odds ratio, 19.33; $95 \%$ confidence interval, 2.27-165.65; $p=0.007$; Table 2).

\section{PD-L1-Expressing ICs Were Mainly Macrophages}

We performed IHC staining with CD3, CD66b, and CD68 for consecutive slides of the HCC tissues with high PD-L1 expression in ICs. We found PD-L1-expressing ICs were mainly located around the tumor-invasive margins, and their distributions were corresponding to 


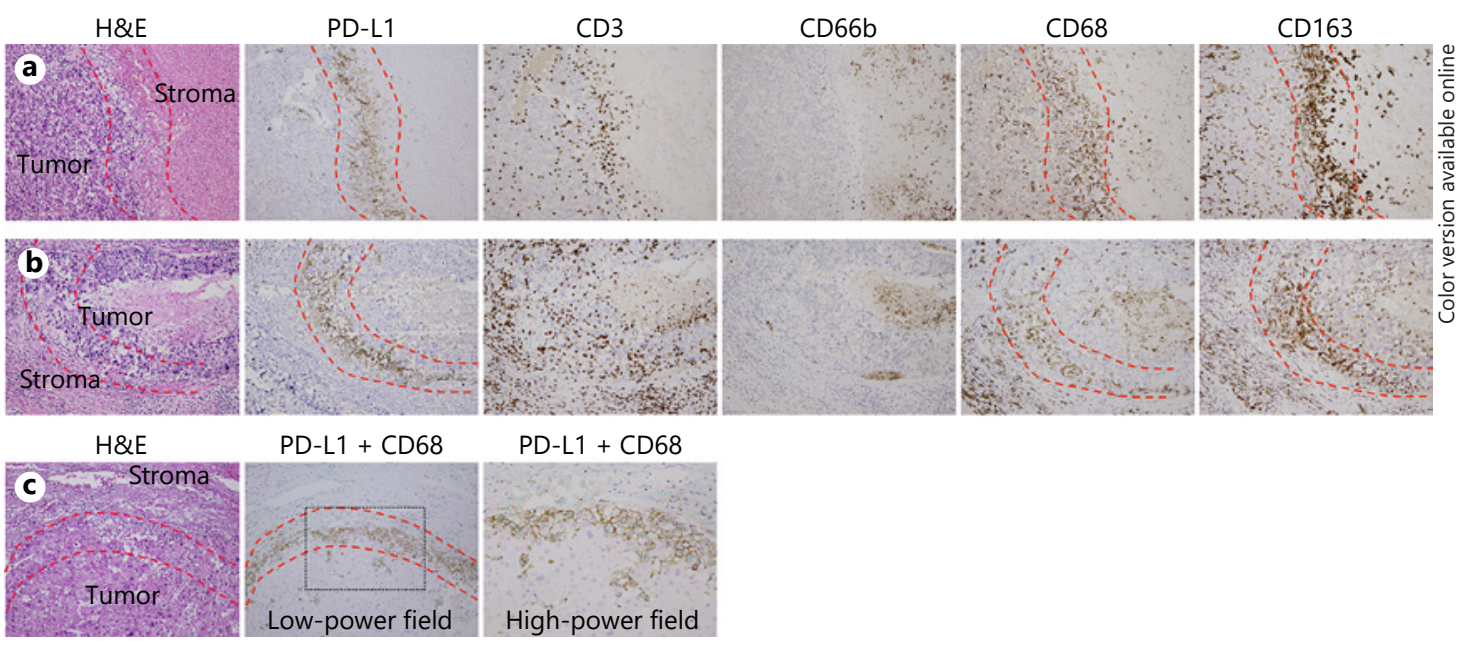

Fig. 3. Representative patients with advanced hepatocellular carcinoma with high expression of programmed death-ligand 1 (PD-L1) in tumor-infiltrating immune cells (ICs). Consecutive slides of the patient with peritoneal metastasis (a) and the patient with lung metastasis (b) were stained with H\&E, PD-L1, CD3, CD66b, CD68, and CD163, respectively. PD-L1-expressing ICs were mainly located around the tumor-invasive margins, and their distributions were highly corresponding to the staining pattern of CD68 and CD163, but not those of CD3 and CD66b. c Consecutive slides of another patient with colonic metastasis were stained with H\&E and were double-stained with PD-L1 and CD68, which were shown in low- and high-power fields. A majority of the PD-L1-positive cells (brown, membranous) around the tumor margin coexpressed CD68 (green, cytoplasmic). The dashed red lines represent the area of invasive margins. The dashed black square in c indicates the area of high-power field.

Table 2. Factors associated with increased PD-L1 expression in tumor-infiltrating immune cells in paired HCC tissues in the multiple logistic regression model

\begin{tabular}{lll}
\hline & Odds ratio $(95 \% \mathrm{CI})$ & $p$ value \\
\hline Sorafenib (yes vs. no) & $19.33(2.26,165.65)$ & 0.007 \\
Tissue 1 (from liver vs. metastasis) & $20.00(1.85,216.17)$ & 0.014 \\
\hline
\end{tabular}

the staining pattern of CD68, but not those of CD3 and CD66b. This observation suggested that the PD-L1-expressing ICs were mainly CD68-positive macrophages, but not T lymphocytes or neutrophils. In the double staining IHC studies on high PD-L1 cases, we confirmed the coexpression of PD-L1 and CD68 on these cells. We further performed IHC staining of CD163 (a marker of M2 macrophages) for consecutive slides of HCC tissues with highly colocalized PD-L1 and CD68 expression. We found the distribution of CD163 expression corresponded to that of CD68 expression. Overall, these data suggest that the PD-L1-expressing ICs in HCC tissues could be M2 macrophages. Representative cases of post-sorafenib tissues with high PD-L1 expression in ICs are shown in Figure 3.

For further profiling of the expression of immune-related genes, 5 pairs of pre- and postsorafenib samples in the study group were analyzed by the nCounter platform (NanoString Technologies, Inc.) using the PanCancer Immune Profiling Panel that includes 770 immunerelated genes. The expression level of CD274, the coding gene of PD-L1, in post-sorafenib samples was significantly higher than in pre-sorafenib samples (ratio, 2.29; $p=0.031$ ). Postsorafenib samples tended to have higher expression of multiple ICs, including macrophages, than pre-sorafenib samples (Fig. 4). 


\section{Liver Cancer}

Fig. 4. Immune gene expression profiling by the nCounter Analysis System. Post-sorafenib samples tended to have higher expression of multiple immune cells, including macrophages, than pre-sorafenib samples.

\begin{tabular}{l|l}
\hline Liver Cancer 2019;8:110-120 \\
\hline DOI: 10.1159/000489021 & $\begin{array}{l}\text { @ 2018 S. Karger AG, Basel } \\
\text { www.karger.com/lic }\end{array}$ \\
\hline
\end{tabular}

Lu et al.: Increased PD-L1 Expression in ICs of HCC after Sorafenib

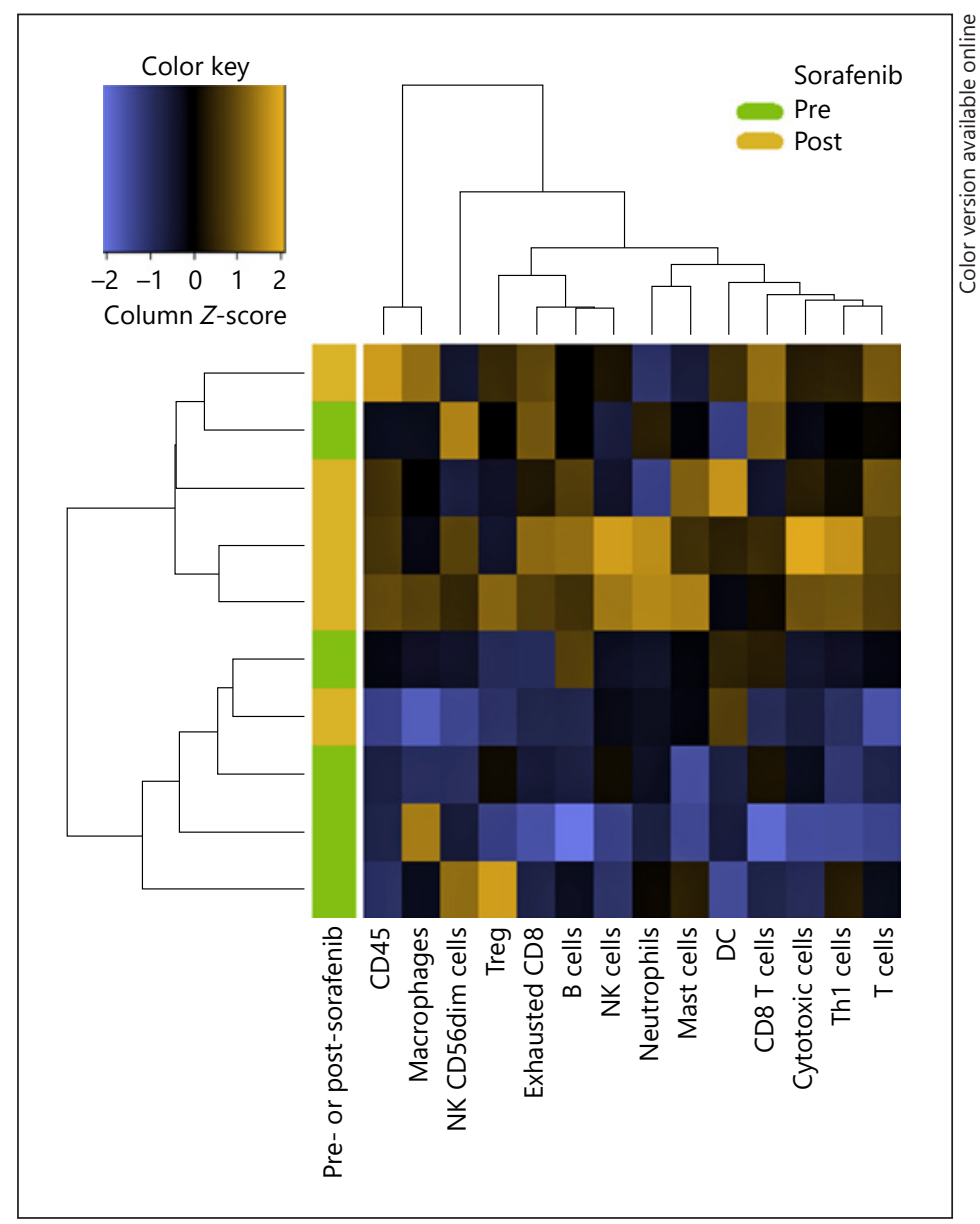

\section{Discussion}

In this study, we found that PD-L1 expression in ICs increased in HCC tissues after sorafenib treatment. However, PD-L1 expression in TCs did not significantly increase after sorafenib treatment. The increased expression of PD-L1 in ICs was still significant after adjustment for the imbalance of tissue origins between the study and reference groups. In selected samples, we demonstrated that PD-L1-expressing ICs were highly colocalized with tumor-infiltrating macrophages.

In the era of immunotherapy, PD-L1 expression in the TME of solid tumors has been evaluated as a biomarker for predicting the efficacy of PD-1/PD-L1 blockade. High PD-L1 expression in TME was associated with an improved response to anti-PD-1 monoclonal antibody therapies in patients with metastatic melanoma or non-small cell lung cancer [21, 22]. However, the recent CheckMate 040 trial showed no significant association between the PD-L1 expression levels in TCs using $1 \%$ as a cut-off and the tumor responses in patients with advanced HCC who received nivolumab, an anti-PD-1 monoclonal antibody [8]. According to our study, the rates of positive PD-L1 expression were generally higher in ICs than TCs. Additional studies investigating PD-L1 as a predictive biomarker of HCC should consider evaluating both TCs and ICs.

In a surgical cohort of patients with HCC, Kuang et al. [23] found that late-stage HCC had higher levels of PD-L1-expressing monocytes or macrophages in the peritumor stroma than 


\section{Liver

early stage HCC, and the increase in these cells was associated with tumor recurrence and reduced survival of the patients. Mechanistically, they found autocrine tumor necrosis factor- $\alpha$ (TNF- $\alpha$ ) and interleukin-10 (IL-10) induced PD-L1 expression of the monocytes. They also demonstrated that these PD-L1-positive monocytes could suppress tumor-specific T cell immunity, and blocking PD-L1 on these monocytes inhibited HCC tumor growth in vivo [23]. In another study, Zhang et al. [24] showed that cytokines or chemokines such as colony-stimulating factor-1, stromal-derived factor- $1 \alpha$, and vascular endothelial growth factor were elevated in the sorafenib-treated HCC xenograft tumors, and contributed to the increase in intratumoral macrophage infiltration. Our current study suggested that macrophages, probably M2 type, were the dominant ICs expressing PD-L1 in the TME of advanced HCC after progression on sorafenib treatment. In our recently published paper employing a syngeneic mouse HCC model in immunocompetent mice, we found the liver tumors exhibited an increase in multiple cytokines, including transforming growth factor- $\beta$, TNF- $\alpha$, IL-10, and interferon- $\gamma$, after sorafenib treatment [25]. Whether these cytokines induce adaptive immunity and increase PD-L1 expression in surrounding ICs, such as macrophages, needs further investigation. Taken together, these findings suggest that PD-L1-expressing macrophages may play a role in immunosuppression and mediating disease progression of HCC after sorafenib treatment.

In our study, we used the clone SP142 as the IHC antibody to determine PD-L1 expression. A phase 2 clinical trial testing atezolizumab, an anti-PD-L1 monoclonal antibody, used SP142 for PD-L1 IHC staining in patients with advanced urothelial cancer and found that high PD-L1 IHC staining predicted an improved outcome, particularly when PD-L1 expression in ICs was evaluated [26]. A study comparing the performance of four PD-L1 IHC antibodies, including 28-8, 22C3, E1L3N, and SP142, with their corresponding platforms showed that the SP142 antibody detected less PD-L1 expression in TCs and ICs in non-small cell lung cancer patient samples than the other antibodies did [27]. However, another study evaluating the performance of different anti-PD-L1 antibodies using optimal assay concentrations found a high concordance among different antibodies including SP142, suggesting that the variation among different PD-L1 IHC antibodies may be attributed to tumor heterogeneity, assay- or platform-specific variables [28]. In our study, when PD-L1 expression in 1\% of TCs was used as a cut-off point, the positive rate $(17.9 \%, 24 / 134)$ was comparable with the PD-L1 positive rate $(16.6 \%, 36 / 217)$ reported in a previous study of HCC patient samples using E1L3N antibody [13].

Our study had limitations. First, the patient number of our study group is small, so the change of PD-L1 expression in TCs after sorafenib may be underestimated. Because the survival of patients with advanced HCC after progression on sorafenib treatment is generally short, it is inherently difficult to identify many patients who have adequate pre- and postsorafenib tissues. Second, the patients enrolled in the study group of this study may represent a unique subgroup of HCC patients [29, 30]. Most of our patients had good performance status and could receive metastatectomy in certain clinical situations. The observation made from this highly selected patient population may not be applicable to most HCC patients. Third, the origins of our tumor tissues were heterogeneous. Additional large patient cohort studies are needed to validate our findings, and to address the question whether tissue origins could influence the immune contexture of HCC. Finally, the distribution of PD-L1-positive cells could be heterogeneous, and we did not adopt digitalized imaging or computerized methods to quantify the percentage of PD-L1-expressing cells. Because TCs and ICs are evaluated separately, pathologist-based assessment is still the current standard employed in research or clinical trials $[20,26]$. To decrease the potential bias in scoring in our study, 2 expert pathologists independently evaluated membranous PD-L1 staining.

In summary, our study demonstrated that increased PD-L1 expression in ICs, mainly being macrophages, was associated with HCC progression after sorafenib treatment. Further 
Lu et al.: Increased PD-L1 Expression in ICs of HCC after Sorafenib

investigation is required to determine the mechanisms underlying this increased PD-L1 expression and the significance of PD-L1-expressing macrophages in the systemic therapy for HCC.

\section{Acknowledgments}

This study was supported by grants from the Ministry of Science and Technology, Taiwan (MOST1052314-B-002-186-MY3, MOST 106-2314-B-002-210) and NTUH (NTUH. 105-M3232, NTUH. 106-S3596). The authors acknowledge statistical assistance provided by the Department of Medical Research, NTUH.

\section{Disclosure Statement}

C.-H. Hsu: consulting or advisor role for Merck Serono and Novartis, receiving honorarium from BristolMyers Squibb and Bayer; A.-L. Cheng: consultant of Novartis, Merck Serono, Eisai, Merck Sharp \& Dohme (I.A.) Corp., ONXEO, Bayer, Bristol-Myers Squibb, and Ono Pharmaceutical Co., Ltd.

\section{References}

1 Llovet JM, Ricci S, Mazzaferro V, Hilgard P, Gane E, Blanc JF, de Oliveira AC, Santoro A, Raoul JL, Forner A, Schwartz M, Porta C, Zeuzem S, Bolondi L, Greten TF, Galle PR, Seitz JF, Borbath I, Haussinger D, Giannaris T, Shan M, Moscovici M, Voliotis D, Bruix J: Sorafenib in advanced hepatocellular carcinoma. N Engl J Med 2008; 359:378-390.

2 Cheng AL, Kang YK, Chen Z, Tsao CJ, Qin S, Kim JS, Luo R, Feng J, Ye S, Yang TS, Xu J, Sun Y, Liang H, Liu J, Wang J, Tak WY, Pan H, Burock K, Zou J, Voliotis D, Guan Z: Efficacy and safety of sorafenib in patients in the AsiaPacific region with advanced hepatocellular carcinoma: a phase III randomised, double-blind, placebocontrolled trial. Lancet Oncol 2009;10:25-34.

3 Bruix J, Qin S, Merle P, Granito A, et al: Regorafenib for patients with hepatocellular carcinoma who progressed on sorafenib treatment (RESORCE): a randomised, double-blind, placebo-controlled, phase 3 trial. Lancet 2017;389:56-66.

4 Kudo M, Finn RS, Qin S, Han KH, Ikeda K, Piscaglia F, Baron AD, Park JW, Han G, Jassem J, Blanc JF, Vogel A, Komov D, Evans TJ, López C, Dutcus CE, Guo M, Saito K, Kraljevic S, Tamai T, Ren M, Cheng AL: Lenvatinib versus sorafenib in first-line treatment of patients with unresectable hepatocellular carcinoma: a randomised phase 3 non-inferiority trial. Lancet DOI 10.1016/S0140-6736(18)30207-1.

5 Sharma P, Allison JP: The future of immune checkpoint therapy. Science 2015;348:56-61.

6 Topalian SL, Drake CG, Pardoll DM: Immune checkpoint blockade: a common denominator approach to cancer therapy. Cancer Cell 2015;27:450-461.

7 Sangro B, Gomez-Martin C, de la Mata M, Inarrairaegui M, Garralda E, Barrera P, Riezu-Boj JI, Larrea E, Alfaro C, Sarobe P, Lasarte JJ, Perez-Gracia JL, Melero I, Prieto J: A clinical trial of CTLA-4 blockade with tremelimumab in patients with hepatocellular carcinoma and chronic hepatitis C. J Hepatol 2013;59:81-88.

8 El-Khoueiry AB, Sangro B, Yau T, Crocenzi TS, Kudo M, Hsu C, Kim TY, Choo SP, Trojan J, Welling THR, Meyer T, Kang YK, Yeo W, Chopra A, Anderson J, Dela Cruz C, Lang L, Neely J, Tang H, Dastani HB, Melero I: Nivolumab in patients with advanced hepatocellular carcinoma (CheckMate 040): an open-label, non-comparative, phase 1/2 dose escalation and expansion trial. Lancet 2017;389:2492-2502.

9 Sprinzl MF, Galle PR: Immune control in hepatocellular carcinoma development and progression: role of stromal cells. Semin Liver Dis 2014;34:376-388.

10 Nakagawa H, Maeda S: Inflammation- and stress-related signaling pathways in hepatocarcinogenesis. World J Gastroenterol 2012;18:4071-4081.

11 Gao Q, Wang XY, Qiu SJ, Yamato I, Sho M, Nakajima Y, Zhou J, Li BZ, Shi YH, Xiao YS, Xu Y, Fan J: Overexpression of PD-L1 significantly associates with tumor aggressiveness and postoperative recurrence in human hepatocellular carcinoma. Clin Cancer Res 2009;15:971-979.

12 Calderaro J, Rousseau B, Amaddeo G, Mercey M, Charpy C, Costentin C, Luciani A, Zafrani ES, Laurent A, Azoulay D, Lafdil F, Pawlotsky JM: Programmed death ligand 1 expression in hepatocellular carcinoma: relationship with clinical and pathological features. Hepatology 2016;64:2038-2046.

13 Chen ML, Yan BS, Lu WC, Chen MH, Yu SL, Yang PC, Cheng AL: Sorafenib relieves cell-intrinsic and cell-extrinsic inhibitions of effector T cells in tumor microenvironment to augment antitumor immunity. Int J Cancer 2014; 134:319-331. 
Lu et al.: Increased PD-L1 Expression in ICs of HCC after Sorafenib

14 Cao M, Xu Y, Youn JI, Cabrera R, Zhang X, Gabrilovich D, Nelson DR, Liu C: Kinase inhibitor sorafenib modulates immunosuppressive cell populations in a murine liver cancer model. Lab Invest 2011;91:598-608.

15 Chang CJ, Yang YH, Chiu CJ, Chiang BL, Lee XY, Hsu CH, Cheng AL: Therapeutic effect of sorafenib is attenuated by tumor-infiltrating Ly6G+ myeloid-derived suppressor cells (MDSCs) and is restored by anti-interleukin-6 (IL-6) antibody treatment in an orthotopic mouse liver cancer model. Proc Annu Meet Am Assoc Cancer Res $2015 ; 461$.

16 Chen Y, Liu YC, Sung YC, Ramjiawan RR, Lin TT, Chang CC, Jeng KS, Chang CF, Liu CH, Gao DY, Hsu FF, Duyverman AM, Kitahara S, Huang P, Dima S, Popescu I, Flaherty KT, Zhu AX, Bardeesy N, Jain RK, Benes CH, Duda DG: Overcoming sorafenib evasion in hepatocellular carcinoma using CXCR4-targeted nanoparticles to co-deliver MEK-inhibitors. Sci Rep 2017;7:44123.

17 Liu J, Liu Y, Meng L, Liu K, Ji B: Targeting the PD-L1/DNMT1 axis in acquired resistance to sorafenib in human hepatocellular carcinoma. Oncol Rep 2017;38:899-907.

18 Osman TA, Oijordsbakken G, Costea DE, Johannessen AC: Successful triple immunoenzymatic method employing primary antibodies from same species and same immunoglobulin subclass. Eur J Histochem 2013; 57:e22.

19 Powles T, Eder JP, Fine GD, Braiteh FS, Loriot Y, Cruz C, Bellmunt J, Burris HA, Petrylak DP, Teng SL, Shen X, Boyd Z, Hegde PS, Chen DS, Vogelzang NJ: MPDL3280A (anti-PD-L1) treatment leads to clinical activity in metastatic bladder cancer. Nature 2014;515:558-562.

20 Herbst RS, Soria JC, Kowanetz M, Fine GD, Hamid O, Gordon MS, Sosman JA, McDermott DF, Powderly JD, Gettinger SN, Kohrt HE, Horn L, Lawrence DP, Rost S, Leabman M, Xiao Y, Mokatrin A, Koeppen H, Hegde PS, Mellman I, Chen DS, Hodi FS: Predictive correlates of response to the anti-PD-L1 antibody MPDL3280A in cancer patients. Nature 2014;515:563-567.

21 Daud AI, Wolchok JD, Robert C, Hwu WJ, Weber JS, Ribas A, Hodi FS, Joshua AM, Kefford R, Hersey P, Joseph R, Gangadhar TC, Dronca R, Patnaik A, Zarour H, Roach C, Toland G, Lunceford JK, Li XN, Emancipator K, DolledFilhart M, Kang SP, Ebbinghaus S, Hamid O: Programmed death-ligand 1 expression and response to the antiprogrammed death 1 antibody pembrolizumab in melanoma. J Clin Oncol 2016;34:4102-4109.

22 Borghaei H, Paz-Ares L, Horn L, Spigel DR, Steins M, Ready NE, Chow LQ, Vokes EE, Felip E, Holgado E, Barlesi F, Kohlhaufl M, Arrieta O, Burgio MA, Fayette J, Lena H, Poddubskaya E, Gerber DE, Gettinger SN, Rudin CM, Rizvi N, Crino L, Blumenschein GR Jr, Antonia SJ, Dorange C, Harbison CT, Graf Finckenstein F, Brahmer JR: Nivolumab versus docetaxel in advanced nonsquamous non-small-cell lung cancer. N Engl J Med 2015;373: 1627-1639.

23 Kuang DM, Zhao Q, Peng C, Xu J, Zhang JP, Wu C, Zheng L: Activated monocytes in peritumoral stroma of hepatocellular carcinoma foster immune privilege and disease progression through PD-L1. J Exp Med 2009;206: 1327-1337.

24 Zhang W, Zhu XD, Sun HC, Xiong YQ, Zhuang PY, Xu HX, Kong LQ, Wang L, Wu WZ, Tang ZY: Depletion of tumorassociated macrophages enhances the effect of sorafenib in metastatic liver cancer models by antimetastatic and antiangiogenic effects. Clin Cancer Res 2010;16:3420-3430.

25 Chang CJ, Yang YH, Chiu CJ, Lu LC, Liao CC, Liang CW, Hsu CH, Cheng AL: Targeting tumor-infiltrating Ly6G+ myeloid cells improves sorafenib efficacy in mouse orthotopic hepatocellular carcinoma. Int J Cancer 2018; 142:1878-1889.

26 Rosenberg JE, Hoffman-Censits J, Powles T, van der Heijden MS, et al: Atezolizumab in patients with locally advanced and metastatic urothelial carcinoma who have progressed following treatment with platinumbased chemotherapy: a single-arm, multicentre, phase 2 trial. Lancet 2016;387:1909-1920.

27 Rimm DL, Han G, Taube JM, Yi ES, Bridge JA, Flieder DB, Homer R, West WW, Wu H, Roden AC, Fujimoto J, Yu H, Anders R, Kowalewski A, Rivard C, Rehman J, Batenchuk C, Burns V, Hirsch FR, Wistuba II: A prospective, multi-institutional, pathologist-based assessment of 4 immunohistochemistry assays for PD-L1 expression in non-small cell lung cancer. JAMA Oncol 2017;3:1051-1058.

28 Gaule P, Smithy JW, Toki M, Rehman J, Patell-Socha F, Cougot D, Collin P, Morrill P, Neumeister V, Rimm DL: A quantitative comparison of antibodies to programmed cell death 1 ligand 1. JAMA Oncol 2017;3:256-259.

29 Shao YY, Wu CH, Lu LC, Chan SY, Ma YY, Yen FC, Hsu CH, Cheng AL: Prognosis of patients with advanced hepatocellular carcinoma who failed first-line systemic therapy. J Hepatol 2014;60:313-318.

30 Lu LC, Shao YY, Chan SY, Hsu CH, Cheng AL: Clinical characteristics of advanced hepatocellular carcinoma patients with prolonged survival in the era of anti-angiogenic targeted-therapy. Anticancer Res 2014;34: 1047-1052. 